Original Article

\title{
Efficacies of ultrasound and a handheld dynamometer to predict one-repetition maximum
}

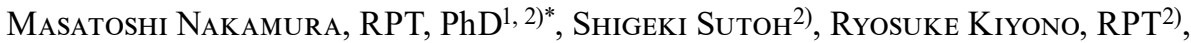 \\ Shigeru Sato, RPT ${ }^{2)}$, KaOru Yahata ${ }^{2)}$, KaKeru Hiraizumi ${ }^{2)}$, \\ SHINICHIRO MORISHITA, RPT, $\mathrm{PhD}^{1,2)}$ \\ 1) Institute for Human Movement and Medical Sciences, Niigata University of Health and Welfare: 1398 \\ Shimami-cho, Kita-ku, Niigata-shi, Niigata 950-3198, Japan \\ 2) Department of Physical Therapy, Niigata University of Health and Welfare, Japan
}

\begin{abstract}
Purpose] It is important to accurately measure one-repetition maximum to determine the training load and number of repetitions. However, huge and expensive equipment, such as a torque machine and/or dynamometer, is needed to measure one-repetition maximum. Therefore, a more accessible and affordable method has been developed to predict one-repetition maximum. In this study, we aimed to investigate whether one-repetition maximum of the knee extensor could be predicted more accurately with a combination of muscle strength, measured using a handheld dynamometer, muscle thickness, and thigh circumference. [Participants and Methods] Participants were sixty-four non-athletic healthy adult volunteers (33 males and 31 females). Muscle strength of the knee extensor measured using one-repetition maximum, maximal voluntary isometric contraction measured using a handheld dynamometer, muscle thickness of the quadriceps and/or thigh circumference measured on ultrasonography. [Results] The stepwise regression analysis revealed that body mass, gender, muscle thickness at $15 \mathrm{~cm}$ above the patella, and maximal voluntary isometric contraction were the significant and independent determinants $\left(\mathrm{R}^{2}=0.813\right)$. [Conclusion] One-repetition maximum could be predicted more accurately with a combination of maximal voluntary isometric contraction measured using a handheld dynamometer and muscle thickness. Key words: One-repetition maximum, Muscle thickness, Handheld dynamometer
\end{abstract}

(This article was submitted May 8, 2019, and was accepted Jul. 4, 2019)

\section{INTRODUCTION}

Skeletal muscle mass is an important factor that influences force capacity and muscle function, which declines with aging, the presence of disease, and disuse. Especially, sarcopenia, known as a decline in skeletal muscle mass and/or strength related to aging, is associated with the risk of falls, fracture, and mortality ${ }^{1-3)}$. In general, high-intensity resistance training with at least $60-80 \%$ one-repetition maximum (1RM) has been prescribed to prevent atrophy and/or increase muscle mass ${ }^{4,5)}$. Interestingly, however, previous study showed that high-repetition and low-intensity resistance training (30\% 1RM) resulted in increased muscle mass and strength ${ }^{6}$. Therefore, training load and the number of repetition should be taken into consideration when prescribing resistance training.

$1 \mathrm{RM}$ is defined as the maximum load that can be moved throughout a full range of motion without deviating from proper form and can be measured using a torque machine or a dynamometer. It is important to measure 1RM accurately in order to determine the training load and the number of repetition ${ }^{7-10}$. In addition, there have been some studies on $1 \mathrm{RM}$ measurement

*Corresponding author. Masatoshi Nakamura (E-mail: masatoshi-nakamura@nuhw.ac.jp)

(C2019 The Society of Physical Therapy Science. Published by IPEC Inc.

(c) (i) $\odot$ This is an open-access article distributed under the terms of the Creative Commons Attribution Non-Commercial No DerivaCC BY NC ND tives (by-nc-nd) License. (CC-BY-NC-ND 4.0: https://creativecommons.org/licenses/by-nc-nd/4.0/) 
among the elderly and clinical population ${ }^{11,12)}$. However, 1RM measurement has led to an increased risk of musculoskeletal injury and elevated blood pressure among the elderly and clinical population with debility. Therefore, in estimating 1RM by submaximal effort, a method that predicts $1 \mathrm{RM}$ from multiple RM tests has been developed ${ }^{13)}$. However, huge and expensive equipment, such as the torque machine and/or dynamometer, is needed to perform multiple RM tests. This equipment may be unavailable in hospitals and rehabilitation centers. Therefore, a more accessible and affordable method is developed to predict $1 \mathrm{RM}$.

In previous studies, the handheld dynamometer (HDD) was reported to be an accessible and inexpensive instrument that is used to measure maximum voluntary isometric contraction (MVIC) strength for 1RM prediction. Specifically, Tan et al. reported that 1RM of knee extensors and elbow flexors were predicted more accurately by MVIC as measured using HHD $^{8)}$. In addition, Kanada et al. reported that 1RM was predicted more accurately by a combination of MVIC and body composition measurements than by MVIC measurement only ${ }^{7}$. Taken together, it is assumed that MVIC measured by HHD could provide an accurate 1RM prediction. However, although MVIC measurement is easy and inexpensive, participants still need to perform 1RM with maximum effort. Therefore, it is important for therapists and coaches to establish a 1RM prediction method that requires less effort and low muscle contraction.

In this study, we measured muscle thickness and/or thigh circumference through ultrasonography. These measurements were noninvasive and required minimal effort or cooperation from the participants. In previous studies, a significant relationship between MVIC and muscle thickness measured through ultrasonography was reported ${ }^{14)}$. Therefore, 1RM could be predicted by muscle thickness and/or thigh circumference measurements. In addition, it was likely that 1RM can be predicted more accurately by a combination of muscle thickness and/or thigh circumference measurement and MVIC measurement by HHD than by MVIC only. Therefore, this study aimed to investigate (1) whether 1RM of knee extensor could be predicted by muscle thickness and thigh circumference and (2) whether 1RM could be predicted more accurately by a combination of MVIC and muscle thickness and thigh circumference. This study hypothesized that it was possible to predict 1RM through muscle thickness and thigh circumference and to predict 1RM more accurately by a combination of MVIC and muscle thickness and thigh circumference.

\section{PARTICIPANTS AND METHODS}

Sixty-four healthy adult volunteers who were non-athletes participated in this study [mean \pm standard deviation [SD]: 33 males (age, $21.4 \pm 1.8$ years; height, $170.8 \pm 6.3 \mathrm{~cm}$; body mass, $64.5 \pm 9.5 \mathrm{~kg}$; body mass index [BMI], 21.1 \pm 2.8 ) and 31 females (age, $20.7 \pm 0.8$ years; height, $158.4 \pm 4.9 \mathrm{~cm}$; body mass, $49.4 \pm 5.0 \mathrm{~kg}$; BMI, $19.6 \pm 1.6$ )], all of whom volunteered to participate in this study. All participants were fully informed of the procedures and purpose of the study, and all provided written informed consent. This study was approved by the Ethics Committee at the Niigata University of Health and Welfare in Niigata, Japan (No.18104) and conducted in accordance with the Declaration of Helsinki.

1RM of knee extensor was measured using a leg-extension machine (Cybex VR1, Cybex International Inc., NY, USA). In this study, the participants were placed in a sitting position on a chair ( $70^{\circ}$ hip angle) and were instructed to grasp the sitting board. Prior to 1RM measurement, each subject was instructed to perform a warm-up of five repetitions at $50 \%$ of the participant's predicted 1RM. After this warm-up, 1RM measurements were performed, and the initial load was selected by each subject. The load was increased until the participants could not lift the weight through a full range of motion (knee flexion from $90^{\circ}$ to full extension), without deviating from proper form. 1RM measurements were performed with sufficient rest between trials to avoid fatigue. In this study, 1RM would be determined within 3-5 attempts.

After performing 1RM measurements, MVIC during a 3-sec voluntary contraction of the knee extensor was measured using HHD ( $\mu$-tas F1, ANIMA Co., Tokyo, Japan) in a sitting position with hip and knee flexion of $90^{\circ}$. The isometric strength (Newton, N) was measured three times for 3 seconds, separated by a sufficient rest period. A maximal value was obtained, and torque $(\mathrm{Nm})$ was calculated by multiplying strength $(\mathrm{N})$ by lever arm $(\mathrm{m})$.

Transverse ultrasound images of the quadriceps femoris on the dominant leg were obtained with a B-mode ultrasound imaging device (LOGIQ e V2; GE Healthcare Japan, Tokyo, Japan) and an 8-MHz linear array probe. Participants were completely relaxed and in a supine position, with hip and knee angle extended. The transducer was positioned perpendicular to the longitudinal axis of the quadriceps femoris at 5, 10, and $15 \mathrm{~cm}$ above the patella and the midpoint between the anterior superior iliac spine and the proximal end of the patella ${ }^{6,15}$. Muscle thickness of the quadriceps muscle was defined as the distance between the inner edges of the fascia and femoral bone. To ensure a minimum pressure of the transducer and lesser distortion of the skin and subcutaneous tissues caused by excess compression, a generous amount of contact gel was applied to the skin, and real-time ultrasonic images were observed. In addition, thigh circumference was measured in the same sites as that for muscle thickness measurement using a cloth tape to the nearest $0.1 \mathrm{~cm}$. Muscle thickness and thigh circumference measurements were performed prior to muscle strength measurements.

SPSS (version 24.0; IBM Corp., Armonk, NY, USA) was used for statistical analysis. The Shapiro-Wilk test was used to evaluate the normality of all variables. Firstly, stepwise regression analysis was employed to investigate the associations between 1RM and independent variables, such as age, body mass, height, gender (male, 0; female, 1), muscle thickness, and thigh circumference, in order to clarify whether 1RM can be predicted with muscle thickness or thigh circumference. Secondly, stepwise regression analysis was employed to investigate the associations between 1RM and independent variables, 
such as age, body mass, height, gender (male, 0 ; female, 1), muscle thickness, and thigh circumference, with the addition of MVIC, to establish a more accurate estimation. The variance inflation factor (VIF) was examined to monitor for a multicollinearity effect. The differences were considered statistically significant at an alpha level of 0.05 . Finally, paired t-tests were used to compare the differences between measured and predicted 1RM. Descriptive data are shown as mean \pm SD.

\section{RESULTS}

All variables were shown in Table 1. In addition, the result of stepwise regression analysis has shown that 1RM can be predicted with muscle thickness or thigh circumference, as shown in Table 2. It was also revealed that body mass, gender, and muscle thickness at $15 \mathrm{~cm}$ above the patella were significant and independent determinants. The following estimation formula was created: $1 \mathrm{RM}(\mathrm{kg})=0.548 \times$ body mass $(\mathrm{kg})-9.692 \times$ gender $($ male $=0$, female $=1)+4.427 \times$ muscle thickness at $15 \mathrm{~cm}$ above patella $(\mathrm{cm})-6.79$. The coefficient was $\mathrm{R}^{2}=0.777(\mathrm{p}<0.01)$. In addition, the predicted $1 \mathrm{RM}$ from this formula was $34.1 \pm 11.7(\mathrm{~kg})$, and no significant difference was observed between measured and predicted 1RM $(\mathrm{p}=0.988)$.

The result of the stepwise regression analysis has shown that 1RM can be predicted with all variables, as shown in Table 3. It was revealed that body mass, gender, muscle thickness at $15 \mathrm{~cm}$ above the patella, and MVIC were significant and independent determinants. The following estimation formula was created: $1 \mathrm{RM}(\mathrm{kg})=0.337 \times$ body mass $(\mathrm{kg})-7.842$ $\times$ gender $($ male $=0$, female $=1)+4.087 \times$ muscle thickness at $15 \mathrm{~cm}$ above patella $(\mathrm{cm})+0.056 \times$ MVIC $(\mathrm{Nm})-4.627$. The coefficient was $\mathrm{R}^{2}=0.813(\mathrm{p}<0.01)$. In addition, the predicted $1 \mathrm{RM}$ from this formula was $34.0 \pm 12.0(\mathrm{~kg})$, and no significant difference was observed between measured and predicted $1 \mathrm{RM}(\mathrm{p}=0.961)$.

Table 1. All variables for measurement

\begin{tabular}{lcc}
\hline & Mean \pm SD & Range \\
\hline 1 RM $(\mathrm{kg})$ & $34.1 \pm 13.2$ & $12.5-74.0$ \\
MVIC $(\mathrm{Nm})$ & $179.7 \pm 71.4$ & $85.0-413.4$ \\
Muscle thickness $(\mathrm{cm})$ & & \\
$5 \mathrm{~cm}$ above patella & $1.74 \pm 0.44$ & $1.01-3.06$ \\
$10 \mathrm{~cm}$ above patella & $2.49 \pm 0.54$ & $1.33-4.04$ \\
$15 \mathrm{~cm}$ above patella & $3.19 \pm 0.60$ & $1.95-5.17$ \\
Midpoint & $3.95 \pm 0.66$ & $2.61-5.74$ \\
Thigh circumference (cm) & & \\
$5 \mathrm{~cm}$ above patella & $39.2 \pm 3.2$ & $32.5-48.5$ \\
$10 \mathrm{~cm}$ above patella & $43.6 \pm 3.8$ & $35.0-55.5$ \\
15 cm above patella & $48.0 \pm 4.1$ & $38.5-61.0$ \\
Midpoint & $52.2 \pm 4.3$ & $44.0-67.5$ \\
\hline RM: repetition maximum; MVIC: maximum voluntary isometric contraction.
\end{tabular}

Table 2. Results of stepwise regression analysis showing that $1 \mathrm{RM}$ can be predicted with muscle thickness or thigh circumference

\begin{tabular}{|c|c|c|c|c|c|c|c|c|}
\hline \multirow[b]{2}{*}{$\begin{array}{l}\text { Dependent } \\
\text { variables: } \\
1 \mathrm{RM}(\mathrm{kg})\end{array}$} & \multirow[b]{2}{*}{$\begin{array}{l}\text { Independent } \\
\text { variables }\end{array}$} & \multirow[b]{2}{*}{$\begin{array}{c}\text { Partial regression } \\
\text { coefficient } \\
\text { (B) }\end{array}$} & \multirow[b]{2}{*}{$\begin{array}{c}\text { Standard partial } \\
\text { regression coefficient } \\
(\beta)\end{array}$} & \multirow[b]{2}{*}{$\mathrm{T}$ value } & \multirow[b]{2}{*}{$\mathrm{p}$ value } & \multicolumn{2}{|c|}{$\begin{array}{c}95 \% \text { confidence } \\
\text { interval }\end{array}$} & \multirow[b]{2}{*}{ VIF } \\
\hline & & & & & & Lower & Upper & \\
\hline & Body mass (kg) & 0.548 & 0.448 & 4.617 & $<0.01$ & 0.311 & 0.786 & 2.486 \\
\hline & $\begin{array}{l}\text { Gender (male, } 0 \text {; } \\
\text { female, 1) }\end{array}$ & -9.692 & -0.393 & -4.183 & $<0.01$ & -14.327 & -5.056 & 1.992 \\
\hline $\mathrm{R}^{2}=0.777$ & $\begin{array}{l}\text { Muscle thickness } \\
\text { at } 15 \mathrm{~cm} \text { above } \\
\text { patella }(\mathrm{cm})\end{array}$ & 4.427 & 0.201 & 2.6 & $=0.012$ & 1.019 & 7.834 & 1.577 \\
\hline
\end{tabular}

RM: repetition maximum; VIF: variance inflation factor; $\mathrm{R}^{2}$ : coefficient of determination. 
Table 3. Results of stepwise regression analysis showing that $1 \mathrm{RM}$ can be predicted with all variables

\begin{tabular}{|c|c|c|c|c|c|c|c|c|}
\hline \multirow[b]{2}{*}{$\begin{array}{l}\text { Dependent } \\
\text { variables: } \\
1 \mathrm{RM}(\mathrm{kg})\end{array}$} & \multirow[b]{2}{*}{$\begin{array}{l}\text { Independent } \\
\text { variables }\end{array}$} & \multirow[b]{2}{*}{$\begin{array}{l}\text { Partial regression } \\
\text { coefficient } \\
\text { (B) }\end{array}$} & \multirow[b]{2}{*}{$\begin{array}{l}\text { Standard partial re- } \\
\text { gression coefficient } \\
(\beta)\end{array}$} & \multirow[b]{2}{*}{$\mathrm{T}$ value } & \multirow[b]{2}{*}{$\mathrm{p}$ value } & \multicolumn{2}{|c|}{$\begin{array}{l}95 \% \text { confidence } \\
\text { interval }\end{array}$} & \multirow[b]{2}{*}{ VIF } \\
\hline & & & & & & Lower & Upper & \\
\hline & Body mass (kg) & 0.337 & 0.275 & 2.663 & $<0.01$ & 0.084 & 0.59 & 3.311 \\
\hline & $\begin{array}{l}\text { Gender (male, } 0 \text {; } \\
\text { female, } 1 \text { ) }\end{array}$ & -7.842 & -0.294 & -3.548 & $<0.01$ & -12.266 & -3.418 & 2.125 \\
\hline & MVIC (Nm) & 0.056 & 0.303 & 3.343 & 0.001 & 0.023 & 0.09 & 2.548 \\
\hline $\mathrm{R}^{2}=0.813$ & $\begin{array}{l}\text { Muscle thickness } \\
\text { at } 15 \mathrm{~cm} \text { above } \\
\text { patella }(\mathrm{cm})\end{array}$ & 4.087 & 0.185 & 2.593 & $=0.012$ & 0.932 & 7.241 & 1.584 \\
\hline
\end{tabular}

RM: repetition maximum; MVIC: maximum voluntary isometric contraction; VIF: variance inflation factor; $R^{2}$ : coefficient of determination.

\section{DISCUSSION}

After investigating the 1RM prediction method, the main findings of this study were as follows: Firstly, 1RM can be predicted by muscle thickness measurements through ultrasonography, which requires a lesser effort of muscle contraction among subjects. Secondly, 1RM can be predicted more accurately by a combination of MVIC measurement through HHD and muscle thickness measurement, which is more accessible and economical. The results suggested that when prescribing resistance training in hospitals and nursing homes, an easier method of predicting 1RM can be conducted using muscle thickness and MVIC measurement.

In previous studies, a significant relationship between muscle cross-sectional area and muscle thickness measurement through ultrasonography was reported ${ }^{16-18)}$, as well as between isometric or isokinetic muscle strength, and muscle thickness or muscle cross-sectional area ${ }^{19-22)}$. Therefore, 1RM could be predicted by muscle thickness measurement as well as isometric and isokinetic muscle strength. The advantages of ultrasonic measurement included noninvasiveness and lesser effort or cooperation among the participants.

In addition, our results revealed that 1RM could be predicted more accurately by a combination of MVIC and muscle thickness than by MVIC only. These results supported the findings of Tan et al. ${ }^{8)}$ and Kanada et al. ${ }^{7)}$, which reported that MVIC measured by HHD was effective for 1RM prediction. In general, although there was a high reproducibility of MVIC measurement by $\mathrm{HHD}^{23,24)}$, MVIC measurement was the isometric muscle contraction measurement. On the other hand, $1 \mathrm{RM}$ is a technique that measures the ability of muscle force to exercise throughout the full range of motion, and contraction mode is considered different between 1RM and MVIC measurements. Therefore, a poor relationship between 1RM and MVIC may be possible. However, our results showed that 1RM could be predicted by MVIC measurement, which has a different contraction mode, and it became evident that 1RM could be predicted more accurately with a combination of muscle thickness measured through ultrasonography and MVIC.

In prescribing resistance training, it is more preferred to set the training load from 1RM rather than MVIC measurements because a constant load is added to the entire range of training. However, a torque machine or dynamometer is necessary to perform 1RM measurement, which makes it difficult to measure 1RM in hospital or nursing home settings where therapists prescribe resistance training. For this reason, 1RM prediction by muscle thickness and MVIC is a more convenient method. Therefore, further studies need to be conducted to investigate the efficiency of 1RM prediction used to prescribe resistance training.

The following limitations were identified in this study. Since we investigated the relationship between 1RM and MVIC for healthy young adults, it is unclear whether the same regression equation is valid for the elderly or other clinical population. However, it is assumed that 1RM could be predicted by muscle thickness and MVIC in the elderly or clinical population. Therefore, further study is needed to investigate the relationship between 1RM and muscle thickness or MVIC in the elderly or clinical population.

RM measurement is a major component for the evaluation of muscle strength or resistance training prescription. Therefore, we have investigated the relationship between 1RM and muscle thickness, thigh circumference, and MVIC measured through HHD. Our results revealed that $1 \mathrm{RM}$ could be predicted accurately by measuring muscle thickness through ultrasonography; however, 1RM could be predicted more accurately by a combination of MVIC measured by HHD and muscle thickness. Future studies need to be conducted to investigate the effect of resistance training intervention using load setting through the regression equation established in this study. 
Funding and Conflict of interest

None.

\section{REFERENCES}

1) Gale CR, Martyn CN, Cooper C, et al.: Grip strength, body composition, and mortality. Int J Epidemiol, 2007, 36: 228-235. [Medline] [CrossRef]

2) Yamada M, Nishiguchi S, Fukutani N, et al.: Prevalence of sarcopenia in community-dwelling Japanese older adults. J Am Med Dir Assoc, 2013 , 14: 911-915. [Medline] [CrossRef]

3) Landi F, Liperoti R, Russo A, et al.: Sarcopenia as a risk factor for falls in elderly individuals: results from the ilSIRENTE study. Clin Nutr, 2012, 31: 652-658. [Medline] [CrossRef]

4) Ratamess N, Alvar B, Evetoch T, et al. American College of Sports Medicine: American College of Sports Medicine position stand. Progression models in resistance training for healthy adults. Med Sci Sports Exerc, 2009, 41: 687-708. [Medline] [CrossRef]

5) Wernbom M, Augustsson J, Thomeé R: The influence of frequency, intensity, volume and mode of strength training on whole muscle cross-sectional area in humans. Sports Med, 2007, 37: 225-264. [Medline] [CrossRef]

6) Ikezoe T, Kobayashi T, Nakamura M, et al.: Effects of low-load, higher-repetition versus high-load, lower-repetition resistance training not performed to failure on muscle strength, mass, and echo intensity in healthy young men: a time-course study. J Strength Cond Res, 2017. [Medline] [CrossRef]

7) Kanada Y, Sakurai H, Sugiura Y, et al.: Estimation of 1RM for knee extension based on the maximal isometric muscle strength and body composition. J Phys Ther Sci, 2017, 29: 2013-2017. [Medline] [CrossRef]

8) Tan AE, Grisbrook TL, Minaee N, et al.: Predicting 1 repetition maximum using handheld dynamometry. PM R, 2018, 10: 934-941. [Medline] [CrossRef]

9) Verdijk LB, van Loon L, Meijer K, et al.: One-repetition maximum strength test represents a valid means to assess leg strength in vivo in humans. J Sports Sci, 2009, 27: 59-68. [Medline] [CrossRef]

10) Requena B, González-Badillo JJ, de Villareal ES, et al.: Functional performance, maximal strength, and power characteristics in isometric and dynamic actions of lower extremities in soccer players. J Strength Cond Res, 2009, 23: 1391-1401. [Medline] [CrossRef]

11) Rydwik E, Karlsson C, Frändin K, et al.: Muscle strength testing with one repetition maximum in the arm/shoulder for people aged $75+-$ test-retest reliability. Clin Rehabil, 2007, 21: 258-265. [Medline] [CrossRef]

12) Kaelin ME, Swank AM, Adams KJ, et al.: Cardiopulmonary responses, muscle soreness, and injury during the one repetition maximum assessment in pulmonary rehabilitation patients. J Cardiopulm Rehabil, 1999, 19: 366-372. [Medline] [CrossRef]

13) Tan S, Wang J, Liu S: Establishment of the prediction equations of 1RM skeletal muscle strength in 60- to 75-year-old Chinese men and women. J Aging Phys Act, 2015, 23: 640-646. [Medline] [CrossRef]

14) Selva Raj I, Bird SR, Shield AJ: Ultrasound measurements of skeletal muscle architecture are associated with strength and functional capacity in older adults. Ultrasound Med Biol, 2017, 43: 586-594. [Medline] [CrossRef]

15) Ikezoe T, Mori N, Nakamura M, et al.: Age-related muscle atrophy in the lower extremities and daily physical activity in elderly women. Arch Gerontol Geriatr, 2011, 53: e153-e157. [Medline] [CrossRef]

16) Miyatani M, Kanehisa H, Ito M, et al.: The accuracy of volume estimates using ultrasound muscle thickness measurements in different muscle groups. Eur J Appl Physiol, 2004, 91: 264-272. [Medline] [CrossRef]

17) Takai Y, Ohta M, Akagi R, et al.: Validity of ultrasound muscle thickness measurements for predicting leg skeletal muscle mass in healthy Japanese middleaged and older individuals. J Physiol Anthropol, 2013, 32: 12. [Medline] [CrossRef]

18) Miyatani M, Kanehisa H, Kuno S, et al.: Validity of ultrasonograph muscle thickness measurements for estimating muscle volume of knee extensors in humans. Eur J Appl Physiol, 2002, 86: 203-208. [Medline] [CrossRef]

19) Masuda K, Kikuhara N, Takahashi H, et al.: The relationship between muscle cross-sectional area and strength in various isokinetic movements among soccer players. J Sports Sci, 2003, 21: 851-858. [Medline] [CrossRef]

20) Akagi R, Iwanuma S, Hashizume S, et al.: Determination of contraction-induced changes in elbow flexor cross-sectional area for evaluating muscle sizestrength relationship during contraction. J Strength Cond Res, 2015, 29: 1741-1747. [Medline] [CrossRef]

21) Franchi MV, Longo S, Mallinson J, et al.: Muscle thickness correlates to muscle cross-sectional area in the assessment of strength training-induced hypertrophy. Scand J Med Sci Sports, 2018, 28: 846-853. [Medline] [CrossRef]

22) Trezise J, Collier N, Blazevich AJ: Anatomical and neuromuscular variables strongly predict maximum knee extension torque in healthy men. Eur J Appl Physiol, 2016, 116: 1159-1177. [Medline] [CrossRef]

23) Thorborg K, Bandholm T, Hölmich P: Hip- and knee-strength assessments using a hand-held dynamometer with external belt-fixation are inter-tester reliable. Knee Surg Sports Traumatol Arthrosc, 2013, 21: 550-555. [Medline] [CrossRef]

24) Jackson SM, Cheng MS, Smith AR Jr, et al.: Intrarater reliability of hand held dynamometry in measuring lower extremity isometric strength using a portable stabilization device. Musculoskelet Sci Pract, 2017, 27: 137-141. [Medline] [CrossRef] 